\section{MODIFIED \\ ULTRAFILTRATION IMPROVES CEREBRAL METABOLIC RECOVERY AFTER CIRCULATORY ARREST}

Modified ultrafiltration uses hemofiltration of the patient and bypass circuit after separation from cardiopulmonary bypass to reverse hemodilution and edema. This study investigated the effect of modified ultrafiltration on cerebral metabolic recovery after deep hypothermic circulatory arrest. Twenty-six 1-week-old piglets (2 to $3 \mathrm{~kg}$ ) were supported by cardiopulmonary bypass $\left(37^{\circ} \mathrm{C}\right)$ at $100 \mathrm{ml} \cdot \mathrm{kg}^{-1} \cdot \mathrm{min}^{-1}$ and cooled to $18^{\circ} \mathrm{C}$. Animals underwent 90 minutes of circulatory arrest followed by rewarming to $37^{\circ} \mathrm{C}$. After being weaned from cardiopulmonary bypass, animals were divided into three groups: controls ( $n=10$ ); modified ultrafiltration for 20 minutes $(n=9)$; transfusion of hemoconcentrated blood for 20 minutes $(n=7)$. Global cerebral blood flow was measured by xenon 133 clearance methods: stage I-before cardiopulmonary bypass; stage $I-\mathbf{5}$ minutes after cardiopulmonary bypass; and stage III-25 minutes after cardiopulmonary bypass. Cerebral metabolic rate of oxygen consumption, cerebral oxygen delivery, and hematocrit value were calculated for each time point. At point III, the hematocrit value (percent) was elevated above baseline in the ultrafiltration and transfusion groups $(44 \pm 1.8,42 \pm 1.8$ versus $28 \pm$ $1.7,30 \pm 0.7$, respectively, $p<0.05)$. Cerebral oxygen delivery $\left(\mathrm{ml} \cdot 100 \mathrm{gm}^{-1}\right.$. $\mathrm{min}^{-1}$ ) increased significantly above baseline at point III after ultrafiltration (4.98 \pm 0.32 versus $3.85 \pm 0.16, p<0.05)$ or transfusion $(4.59 \pm 0.17$ versus $3.89 \pm 0.06$, $p<0.05)$ and decreased below baseline in the control group $(2.77 \pm 0.19$ versus 3.81 $\pm 0.16, p<0.05$ ). Ninety minutes of deep hypothermic circulatory arrest resulted in impaired cerebral metabolic oxygen consumption $\left(\mathrm{ml} \cdot 100 \mathrm{gm}^{-1} \cdot \mathrm{min}^{-1}\right)$ at point III in the control group $(1.95 \pm 0.15$ versus $2.47 \pm 0.07, p<0.05)$ and transfusion group $(1.72 \pm 0.10$ versus $2.39 \pm 0.15, p<0.05)$. After modified ultrafiltration, however, cerebral metabolic oxygen consumption at point III had increased significantly from baseline $(3.12 \pm 0.24$ versus $2.48 \pm 0.13, p<0.05)$, indicating that the decrease in cerebral metabolism immediately after deep hypothermic circulatory arrest is reversible and may not represent permanent cerebral injury. Use of modified ultrafiltration after cardiopulmonary bypass may reduce brain injury associated with deep hypothermic circulatory arrest. (J THORAC CARDIOVASC SuRG 1995;109:744-52)

Lynne A. Skaryak, MD ${ }^{a}$ (by invitation), Paul M. Kirshbom, $\mathrm{MD}^{\mathrm{a}}$ (by invitation), Louis R. DiBernardo, MD ${ }^{\mathrm{a}}$ (by invitation), Frank H. Kern, MD $^{\mathrm{b}}$ (by invitation), William J. Greeley, $\mathrm{MD}^{\mathrm{b}}$ (by invitation), Ross $\mathrm{M}$. Ungerleider, $\mathrm{MD}^{\mathrm{a}}$ (by invitation), and J. William Gaynor, MD ${ }^{\mathrm{a}}$ (by invitation), Durham, N.C.

Sponsored by David C. Sabiston, Jr., MD, Durham, N.C.
D eep hypothermic circulatory arrest (DHCA) is often used during the repair of complex congenital heart defects in neonates and infants. Transient

From the Departments of Surgery, ${ }^{a}$ Anesthesiology, and Pediatrics,' Duke University Medical Center, Durham, N.C.

Read at the Seventy-fourth Annual Meeting of The American Association for Thoracic Surgery, New York, N.Y., April 24-27, 1994.

Address for reprints: J. William Gaynor, MD, Department of Surgery, Box 2923, Duke University Medical Center, Durham, N.C. 27710.

Copyright (C) 1995 by Mosby-Year Book, Inc.

$0022-5223 / 95 \$ 3.00+0 \quad \mathbf{1 2 / 6 / 6 2 0 4 4}$ and permanent neurologic sequelae may be observed after DHCA. ${ }^{1-3}$ Recent investigations have demonstrated that DHCA results in a decreased cerebral metabolic rate of oxygen consumption $\left(\mathrm{CMRO}_{2}\right)$ after separation from cardiopulmonary bypass (CPB). ${ }^{4,5}$ The decrease in $\mathrm{CMRO}_{2}$ may be related to duration of DHCA as well as other factors and has been used as a marker of cerebral injury. ${ }^{4-8}$ After separation from CPB after DHCA, cerebral hypoperfusion and elevated cerebral vascular resistance impair cerebral oxygen delivery. ${ }^{9-12}$ Cerebral oxygen delivery may also be compromised by a decrease in cardiac output, reduction in hemoglo- 
bin, elevated pulmonary vascular resistance, hypoxemia, and organ edema increasing the risk of neurologic injury during this vulnerable period after CPB.

Modified ultrafiltration (MUF) is a technique that uses ultrafiltration of the patient and hemofiltration of the CPB circuit after separation from bypass to reverse hemodilution occurring during cardiac operations. ${ }^{13,14}$ In children undergoing CPB for repair of congenital heart defects, MUF has been demonstrated to reduce total body water and decrease pulmonary vascular resistance, as well as to increase mean arterial pressure and cardiac index. ${ }^{15,}{ }^{16}$ However, the effects of MUF on cerebral function after DHCA have not been examined. MUF may improve cerebral metabolism in the vulnerable period after DHCA by raising post-CPB hemoglobin values to increase cerebral oxygen delivery. This study investigates the effect of MUF on cerebral metabolic recovery after DHCA in a 1-week-old piglet model.

\section{Methods}

Twenty-eight 1-week-old piglets weighing 2 to $3 \mathrm{~kg}$ were studied with approval of the institution's animal care and use committee and in compliance with the "Guide for the Care and Use of Laboratory Animals" prepared by the Institute of Laboratory Animal Resources and published by the National Institutes of Health (NIH publication No. 85-23, revised 1985). Animals were premedicated with intramuscular ketamine $(20 \mathrm{mg} / \mathrm{kg})$, intubated, and mechanically ventilated (Infant Ventilator; Sechrist Industries, Anaheim, Calif.). Methylprednisolone (40 mg/kg) was given intravenously. After a bolus of intravenous fentanyl $(100 \mu \mathrm{g})$ and pancuronium $(0.1 \mathrm{mg} / \mathrm{kg})$, anesthesia was maintained with continuous fentanyl infusion (50 $\mu \mathrm{g} \cdot \mathrm{kg}^{-1} \cdot \mathrm{hr}^{-1}$ ). A femoral artery catheter was placed for measurement of mean arterial pressure and arterial blood sampling. A median sternotomy was performed and an 8 $\mathrm{mm}$ ultrasonic flow probe (Transonic Systems, Ithaca, N.Y.) was positioned around the main pulmonary artery for measurement of cardiac output. A left atrial catheter was inserted and a temperature probe was placed in the nasopharynx. A burr hole was made in the skull at the crus of the sagittal and coronal sutures to allow sagittal sinus blood sampling.

Hemispheric cerebral blood flow (CBF) was measured by the xenon $\left({ }^{133} \mathrm{Xe}\right)$ clearance technique. ${ }^{17}$ Two extracranial $16 \mathrm{~mm}$ cadmium telluride gamma emission detectors were placed over the right and left temporal lobes. Radioactive xenon $(1.5 \mathrm{mCi}$ in $2 \mathrm{ml}$ of normal saline solution) was injected into the left atrial catheter and radioactive decay recorded from each hemisphere over a 5-minute period. Hemispheric CBF was determined by a modification of the initial slope index method. ${ }^{18}$ By this method, CBF $=($ slope $)(\gamma)(100)$, where slope is the natural logarithm of the ${ }^{133} \mathrm{Xe}$ clearance 1 minute after the peak of the curve, $\gamma$ is the tissue-blood partition coefficient for xenon, corrected for hematocrit and tem-

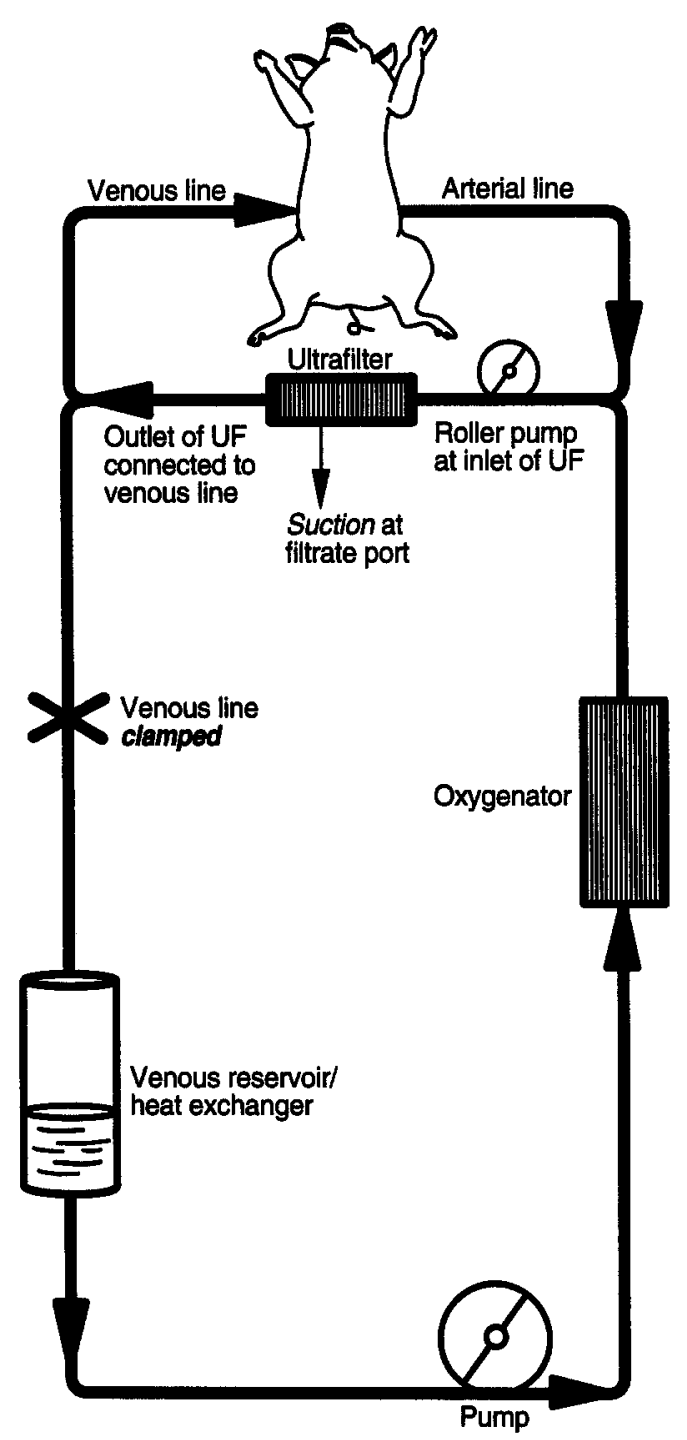

Fig. 1. Modified placement of the hemofilter after separation from CPB and during ultrafiltration. $U F$, Ultrafilter.

perature, ${ }^{19}$ and 100 converts $\mathrm{ml} \cdot \mathrm{gm}^{-1} \cdot \min ^{-1}$ to $\mathrm{ml} \cdot 100$ $\mathrm{gm}^{-1} \cdot \mathrm{min}^{-1}$. Global CBF was determined as the average of the individually calculated hemispheric blood flows. Baseline ${ }^{133} \mathrm{Xe}$ was measured before each determination and subtracted to correct curves for residual xenon.

A schematic diagram of the experimental protocol is shown in Fig. 1. After instrumentation, data were collected before $\mathrm{CPB}$ at $37^{\circ} \mathrm{C}$ (stage I). Animals were then supported by CPB at $100 \mathrm{ml} \cdot \mathrm{kg}^{-1} \cdot \mathrm{min}^{-1}$ at $37^{\circ} \mathrm{C}$ and cooled by perfusion to $17.7^{\circ} \pm 0.1^{\circ} \mathrm{C}$ over a 23 -minute period. All animals underwent 90 minutes of DHCA followed by a rewarming period with a mean duration of $27 \pm 1$ minutes to $36.0^{\circ} \pm 0.2^{\circ} \mathrm{C}$. Animals were weaned from CPB and data were collected 5 minutes after separation from CPB (stage II). Animals were divided into three groups: control $(n=10)$-observation for 20 min- 


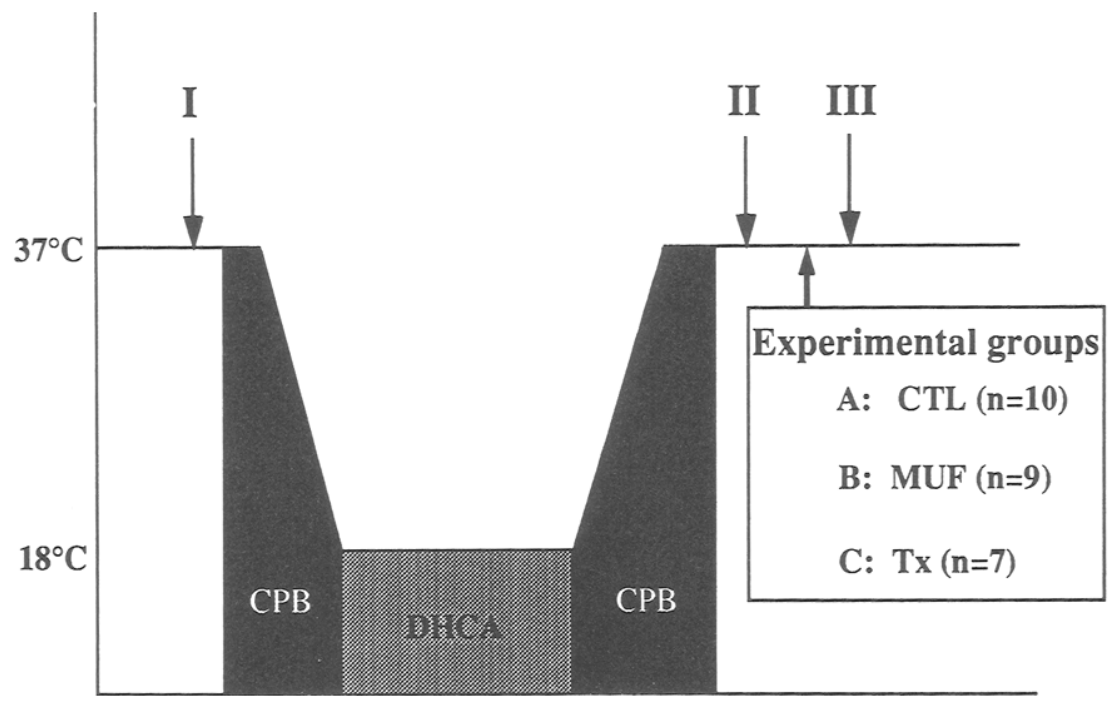

Fig. 2. Experimental protocol and data collection sequence: After instrumentation, baseline measurements $(I)$ were obtained. Animals were supported by CPB at $100 \mathrm{ml} \cdot \mathrm{kg}^{-1} \cdot \mathrm{min}^{-1}$ and $37^{\circ} \mathrm{C}$, and then cooled to $18^{\circ} \mathrm{C}$ over 23 minutes. Animals underwent 90 minutes of $\mathrm{DHCA}$, followed by rewarming to $36^{\circ} \mathrm{C}$ over a 27-minute period. Data were obtained 5 minutes after separation from CPB $(I I)$. The experimental groups were as follows: $A, C T L$, Observation for 20 minutes without intervention $(n=10) ; B, M U F$, modified ultrafiltration for 16 minutes $(n=9) ; C, T x$, transfusion of hemoconcentrated blood over 20 minutes $(n=7)$. Final measurements were then obtained 25 minutes after separation from CPB (III).

utes without intervention; MUF $(n=9)$-MUF for $16 \pm$ 1 minutes; transfusion $(n=7)$-transfusion of nonleukocyte-depleted hemoconcentrated blood over 20 minutes to achieve a hematocrit value greater than $40 \%$. Data were collected 25 minutes after separation from CPB (stage III) (Fig. 2).

Nasopharyngeal temperature, mean arterial pressure, heart rate, cardiac output, left atrial pressure, arterial and sagittal sinus blood gases, hemoglobin concentration, and $\mathrm{CBF}$ were measured at each stage. Brains were not weighed at the completion of the experiment. The cerebral arteriovenous oxygen content difference $\left(\mathrm{cCaO}_{2}-\mathrm{vO}_{2}\right)$ was calculated as $\mathrm{CaO}_{2}-\mathrm{CssO}_{2}$, where $\mathrm{CssO}_{2}$ is the sagittal sinus oxygen content. A GEM-STAT blood gas/electrolyte monitor (Mallinckrodt, Ann Arbor, Mich.) was used to measure blood gases. Oxygen saturation and hemoglobin concentration were measured by an IL 482 CO-Oximeter System (Instrumentation Laboratory, Lexington, Mass.). The $\mathrm{CMRO}_{2}$, cerebral oxygen delivery $\left(\mathrm{cD} \cdot \mathrm{O}_{2}\right)$, and cerebral oxygen extraction ratio $\left(\mathrm{cO}_{2} \mathrm{ER}\right)$ were calculated at each stage as follows:

$$
\begin{gathered}
\mathrm{CMRO}_{2}\left(\mathrm{ml} \cdot 100 \mathrm{gm} \text { brain }^{-1} \cdot \mathrm{min}^{-1}\right)=\left(\mathrm{cCaO}_{2}-\mathrm{vO}_{2}\right)(\mathrm{CBF}) \\
\mathrm{cD} \cdot \mathrm{O}_{2}\left(\mathrm{ml} \mathrm{O}_{2} \cdot 100 \mathrm{gm} \mathrm{brain}^{-1} \cdot \mathrm{min}^{-1}\right)=\left(\mathrm{CaO}_{2}\right)(\mathrm{CBF}) \\
\mathrm{CO}_{2} \mathrm{ER}(\%)=\mathrm{CMRO}_{2} / \mathrm{cD} \cdot \mathrm{O}_{2}
\end{gathered}
$$

Data were analyzed with the Student's paired $t$ test to compare results within each group. The unpaired $t$ test and analysis of variance were used to compared results between groups. All results are expressed as means \pm standard errors. Significance was defined as $p<0.05$.

\section{Results}

The study was successfully completed in 26 of the 28 animals. Two animals were excluded, one for a markedly abnormal baseline $\mathrm{CMRO}_{2}$ value (control) and one for hypotension during MUF, which precluded the ability to complete the study protocol.

No significant differences existed between the groups of animals in mean arterial pressure, heart rate, cardiac output, hematocrit, $\mathrm{CMRO}_{2}$, cerebral oxygen delivery, and cerebral oxygen extraction ratio before CPB (Tables I and II). The baseline nasopharyngeal temperature for the transfusion group was significantly lower than for the other groups, but this was not believed to be of physiologic importance. CBF was slightly but significantly lower in the transfusion group than in the MUF and control groups before CPB $(p<0.05)$. No significant differences in hemodynamic parameters were detectable between animal groups during CPB.

Five minutes after the animals were weaned from $\mathrm{CPB}$, there were no significant differences between groups in mean arterial pressure, cardiac output, 
Table I. Summary data for all animals

\begin{tabular}{llll}
\hline & \multicolumn{1}{c}{$I$} & \multicolumn{1}{c}{$I I$} & \multicolumn{1}{c}{$I I I$} \\
\hline NPT $\left({ }^{\circ} \mathrm{C}\right)$ & & & \\
CTL & $36.9 \pm 0.3$ & $35.7 \pm 0.3 \ddagger$ & $35.0 \pm 0.3 \ddagger \S$ \\
MUF & $36.3 \pm 0.3$ & $35.7 \pm 0.2$ & $34.0 \pm 0.3^{*} \ddagger \S$ \\
Tx & $35.9 \pm 0.2^{*}$ & $35.9 \pm 0.2$ & $34.9 \pm 0.2 \dagger \ddagger \S$ \\
MAP (mm Hg) & & & \\
CTL & $51.6 \pm 2.6$ & $41.3 \pm 3.4 \ddagger$ & $38.6 \pm 2.8 \ddagger$ \\
MUF & $57.2 \pm 2.9$ & $45.4 \pm 2.5$ & $55.2 \pm 1.5^{*}$ \\
Tx & $60.7 \pm 4.2$ & $48.4 \pm 3.4 \ddagger$ & $65.9 \pm 6.1^{*} \S$ \\
HR (beats/min) & & & \\
CTL & $185 \pm 12$ & $163 \pm 3$ & $171 \pm 6$ \\
MUF & $187 \pm 11$ & $170 \pm 5$ & $152 \pm 4^{*} \ddagger \S$ \\
Tx & $162 \pm 9$ & $167 \pm 8$ & $156 \pm 8$ \\
CO (ml/min) & & & \\
CTL & $381 \pm 13$ & $395 \pm 14$ & $356 \pm 22 \S$ \\
MUF & $327 \pm 45$ & $372 \pm 44 \ddagger$ & $366 \pm 42 \ddagger$ \\
Tx & $411 \pm 22$ & $426 \pm 16$ & $426 \pm 45$ \\
LAP (mm Hg) & & & \\
CTL & - & $5 \pm 0.6$ & $4 \pm 0.5$ \\
MUF & - & $6 \pm 0.6$ & $7 \pm 0.8^{*} \S$ \\
Tx & - & $3 \pm 0.3 \dagger$ & $7 \pm 0.8^{*} \S$ \\
\hline
\end{tabular}

Study stages: $I$, Before CPB; II, 5 minutes after CPB; $I I I, 25$ minutes after CPB. Mean values \pm standard error. $N P T$, Nasopharyngeal temperature; $M A P$, mean arterial pressure; $H R$, heart rate; $C O$, cardiac output; $L A P$, left atrial pressure; $C T L$, control; $M U F$, ultrafiltered; $T x$, transfused.

${ }^{*} p<0.05$; MUF and Tx versus CTL.

$p p<0.05$ MUF versus Tx.

$\neq p<0.05$ stages II and III versus I.

$\S p<0.05$ stage III versus II.

hematocrit, $\mathrm{CBF}, \mathrm{CMRO}_{2}$, or cerebral oxygen delivery. The left atrial pressure was significantly lower in the transfusion group than in the other groups $(p<0.05)$. There were no significant differences from pre-CPB baseline values in hematocrit, $\mathrm{CMRO}_{2}$, or cerebral oxygen delivery in any group. The cerebral oxygen extraction ratio increased significantly above pre-CPB value in control animals $(p<0.05)$, whereas values in the MUF and transfusion groups were not different from baseline. CBF had decreased significantly from baseline values in the control and MUF animals $(p<0.05)$.

In the control animals after 20 minutes of observation after separation from CPB (stage III), there was a significant decrease in $\mathrm{CBF}, \mathrm{CMRO}_{2}$, and cerebral oxygen delivery $(p<0.05)$ compared with stage II values (Figs. 3 and 4). Hematocrit, left atrial pressure, and cerebral oxygen extraction ratio, however, did not change significantly from stage II values.

After MUF (stage III), there was a significant increase $(p<0.05)$ in hematocrit, $\mathrm{CMRO}_{2}$, and cerebral oxygen delivery compared with stage I and II values (Figs. 3 and 4). The cerebral oxygen
Table II. Summary data for all animals

\begin{tabular}{cccl}
\hline \multicolumn{1}{c}{$I$} & \multicolumn{1}{c}{$I I$} & \multicolumn{1}{c}{$I I I$} \\
\hline $\mathrm{HCT}$ & & & \\
$\mathrm{CTL}$ & $27 \pm 1$ & $28 \pm 1$ & $28 \pm 2$ \\
$\mathrm{MUF}$ & $28 \pm 2$ & $27 \pm 1$ & $44 \pm 2^{*} \ddagger \S$ \\
$\mathrm{Tx}$ & $30 \pm 1$ & $28 \pm 1$ & $42 \pm 2^{*} \ddagger \S$ \\
$\mathrm{CBF}$ & & & \\
$\mathrm{CTL}$ & $32.1 \pm 0.8$ & $28.4 \pm 1.5 \ddagger$ & $22.4 \pm 1.4 \ddagger \S$ \\
$\mathrm{MUF}$ & $31.8 \pm 1.3$ & $27.8 \pm 1.0 \ddagger$ & $25.5 \pm 1.4 \ddagger$ \\
$\mathrm{Tx}$ & $29.1 \pm 0.8^{*}$ & $28.6 \pm 0.8$ & $25.1 \pm 1.6$ \\
$\mathrm{cD} \cdot \mathrm{O}_{2}$ & & & \\
$\mathrm{CTL}$ & $3.81 \pm 0.16$ & $3.50 \pm 0.24$ & $2.77 \pm 0.19 \ddagger \S$ \\
$\mathrm{MUF}$ & $3.85 \pm 0.16$ & $3.34 \pm 0.13$ & $4.98 \pm 0.32^{*} \ddagger \S$ \\
$\mathrm{Tx}$ & $3.89 \pm 0.06$ & $3.47 \pm 0.35$ & $4.59 \pm 0.17^{*} \ddagger \S$ \\
$\mathrm{CMRO}$ & & \\
$\mathrm{CTL}$ & $2.47 \pm 0.07$ & $2.65 \pm 0.25$ & $1.95 \pm 0.15 \ddagger \S$ \\
$\mathrm{MUF}$ & $2.48 \pm 0.13$ & $2.38 \pm 0.08$ & $3.12 \pm 0.24^{*} \ddagger \S$ \\
$\mathrm{Tx}$ & $2.39 \pm 0.15$ & $1.97 \pm 0.29$ & $1.72 \pm 0.10 \dagger \ddagger$ \\
$\mathrm{cO}{ }_{2} \mathrm{ER}$ & & & \\
$\mathrm{CTL}$ & $59.6 \pm 2.4$ & $67.8 \pm 3.2 \ddagger$ & $64.9 \pm 3.2$ \\
$\mathrm{MUF}$ & $58.6 \pm 3.2$ & $65.0 \pm 2.7$ & $57.5 \pm 2.0 \S$ \\
$\mathrm{Tx}$ & $55.7 \pm 0.5$ & $51.3 \pm 3.7^{*} \dagger$ & $35.1 \pm 2.5^{*} \dagger \ddagger \S$ \\
\hline
\end{tabular}

Study stages: $I$, Before CPB; II, 5 minutes after CPB; $I I I, 25$ minutes after CPB. Mean values \pm standard error. $H C T$, Hematocrit (\%); $C B F$, cerebral blood flow $\left(\mathrm{ml} \cdot 100 \mathrm{gm}^{-1} \cdot \mathrm{min}^{-1}\right) ; C D \cdot O_{2}$ cerebral oxygen delivery $(\mathrm{ml} \cdot 100$ $\left.\mathrm{gm}^{-1} \cdot \min ^{-1}\right) ; \mathrm{CMRO}_{2}$, cerebral metabolic rate of oxygen $\left(\mathrm{ml} \cdot 100 \mathrm{gm}^{-1}\right.$. min); $\mathrm{CO}_{2} E R(\%)$, cerebral oxygen extraction ratio. $C T L$, Control; $M U F$, ultrafiltered; $T x$, transfused.

${ }^{*} p<0.05 ;$ MUF and Tx versus CTL.

$\dagger p<0.05$ MUF versus Tx.

$\neq p<0.05$ stages II and III versus I.

$\S p<0.05$ stage III versus II.

extraction ratio had decreased significantly from stage II $(p<0.05)$. At stage III, $\mathrm{CMRO}_{2}$ was significantly higher in the MUF group than in the control and transfusion animals $(3.12 \pm 0.24$ versus $1.95 \pm 0.15$ and $1.72 \pm 0.10 \mathrm{ml} \cdot 100 \mathrm{gm}^{-1} \cdot \mathrm{min}^{-1}$, $p<0.05$ ), and cerebral oxygen delivery was significantly higher than in control animals (4.98 \pm 0.32 versus $\left.2.77 \pm 0.19 \mathrm{ml} \cdot 100 \mathrm{gm}^{-1} \cdot \min ^{-1}, p<0.05\right)$. However, there was no significant difference in cerebral oxygen delivery between the MUF and transfusion groups $(4.98 \pm 0.32$ versus $4.59 \pm 0.17$ $\left.\mathrm{ml} \cdot 100 \mathrm{gm}^{-1} \cdot \mathrm{min}^{-1}\right)$ at this time.

After transfusion, there was a significant increase in hematocrit and cerebral oxygen delivery from stage II $(p<0.05)$. Despite this increase, $\mathrm{CMRO}_{2}$ decreased significantly compared with measurements in stages I and II $(1.72 \pm 0.10$ versus $2.39 \pm$ 0.15 and $1.97 \pm 0.29 \mathrm{ml} \cdot 100 \mathrm{gm}^{-1} \cdot \mathrm{min}^{-1}, p<$ $0.05)$. The cerebral oxygen extraction ratio in the transfused animals also decreased significantly from stages I and II $(35.1 \% \pm 2.5 \%$ versus $55.7 \% \pm 0.5 \%$ and $51.3 \% \pm 3.7 \%, p<0.05)$ and as compared with measurements in the control and MUF groups 


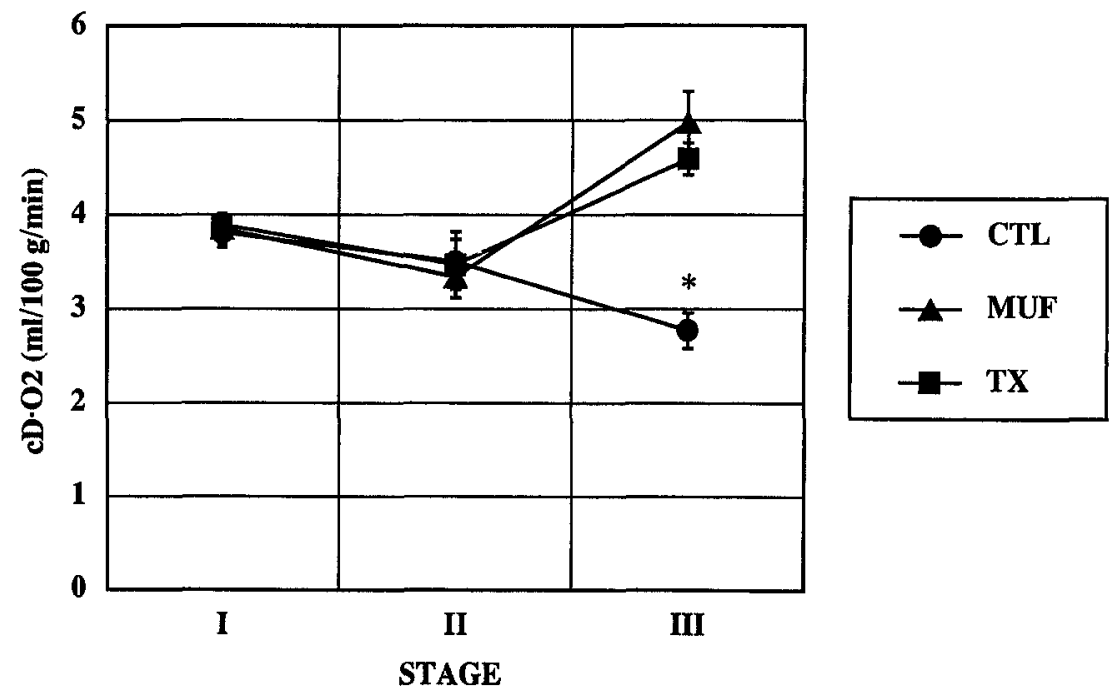

Fig. 3. Cerebral oxygen delivery $\left(\mathrm{cD} \cdot \mathrm{O}_{2}\right)$ measurements before and after DHCA. There was a significant decrease in $\mathrm{cD} \cdot \mathrm{O}_{2}$ in CTL animals compared with MUF and Tx groups at stage III. Mean data \pm standard error; ${ }^{*} p \pm 0.0001$, CTL versus MUF and Tx. $C T L$, Control; $M U F$, ultrafiltration; $T x$, transfusion. $I$, Before CPB; II, 5 minutes after CPB; $I I I, 25$ minutes after CPB.

$(35.1 \% \pm 2.5 \%$ versus $64.9 \% \pm 3.2 \%$ and $57.5 \% \pm$ $2.0 \%, p<0.05)$. There was no significant difference in cerebral oxygen delivery compared with the MUF group at stage III. $\mathrm{CMRO}_{2}$ did not differ significantly from that in control animals at stage III (1.72 \pm 0.10 versus $1.95 \pm 0.15 \mathrm{ml} \cdot 100 \mathrm{gm}^{-1} \cdot \mathrm{min}^{-1}$ ).

There was a difference between hemodynamic parameters between the MUF and transfusion animals versus the control group. Control animals had a significant decline in cardiac output and mean arterial pressure during the 20 -minute period of observation $(p<0.05)$, indicating a deterioration in hemodynamic stability. MUF and transfusion animals were able to maintain cardiac output and mean arterial pressure at pre-CPB values. These differences may be accounted for by the increased left atrial pressure after transfusion and MUF, which was not seen in the control group.

\section{Discussion}

Transient and permanent neuropsychologic injury may occur in up to $25 \%$ of infants undergoing CPB with DHCA. ${ }^{2}$ Most clinical and experimental investigations have focused primarily on the effects of cerebral protection strategies used during the cooling and arrest phases of operations for congenital heart disease. ${ }^{6,7,11-12,20-26}$ Cerebral injury may also occur after arrest in the rewarming period by reperfusion injury and in the period after separation from $\mathrm{CPB}$. The period after separation from $\mathrm{CPB}$ is characterized by cerebral hypoperfusion and elevated cerebral vascular resistance. ${ }^{9-12} \mathrm{~A}$ reduction in $\mathrm{CMRO}_{2}$ has also been demonstrated during this time. ${ }^{4-6}$ An increase in metabolic demand may be needed at this time to repay an oxygen debt incurred during arrest, and further neurologic injury may occur if the brain cannot increase $\mathrm{CMRO}_{2}$ after DHCA. Increasing cerebral oxygen delivery in the period after separation from CPB in an attempt to drive metabolism is one method that might prevent or lessen cerebral injury after DHCA.

This study demonstrates that in this model of neonatal CPB simply increasing cerebral oxygen delivery by raising the hematocrit value does not result in increased $\mathrm{CMRO}_{2}$, and cerebral metabolism remains impaired after DHCA. In fact, control and transfused animals had a similar impairment in cerebral metabolism 25 minutes after separation from CPB after DHCA (Fig. 4). Even though additional oxygen is available for consumption after transfusion, the brain is unable to increase its use of oxygen; therefore, cerebral oxygen extraction decreases. MUF resulted in an increase in cerebral oxygen delivery and $\mathrm{CMRO}_{2}$ above baseline, indicating that oxygen use by the brain is improved. These findings suggest that MUF acts by mechanisms other than an increase in cerebral oxygen delivery to improve oxygen use by the brain after DHCA.

The level of $\mathrm{CMRO}_{2}$ after DHCA necessary for 


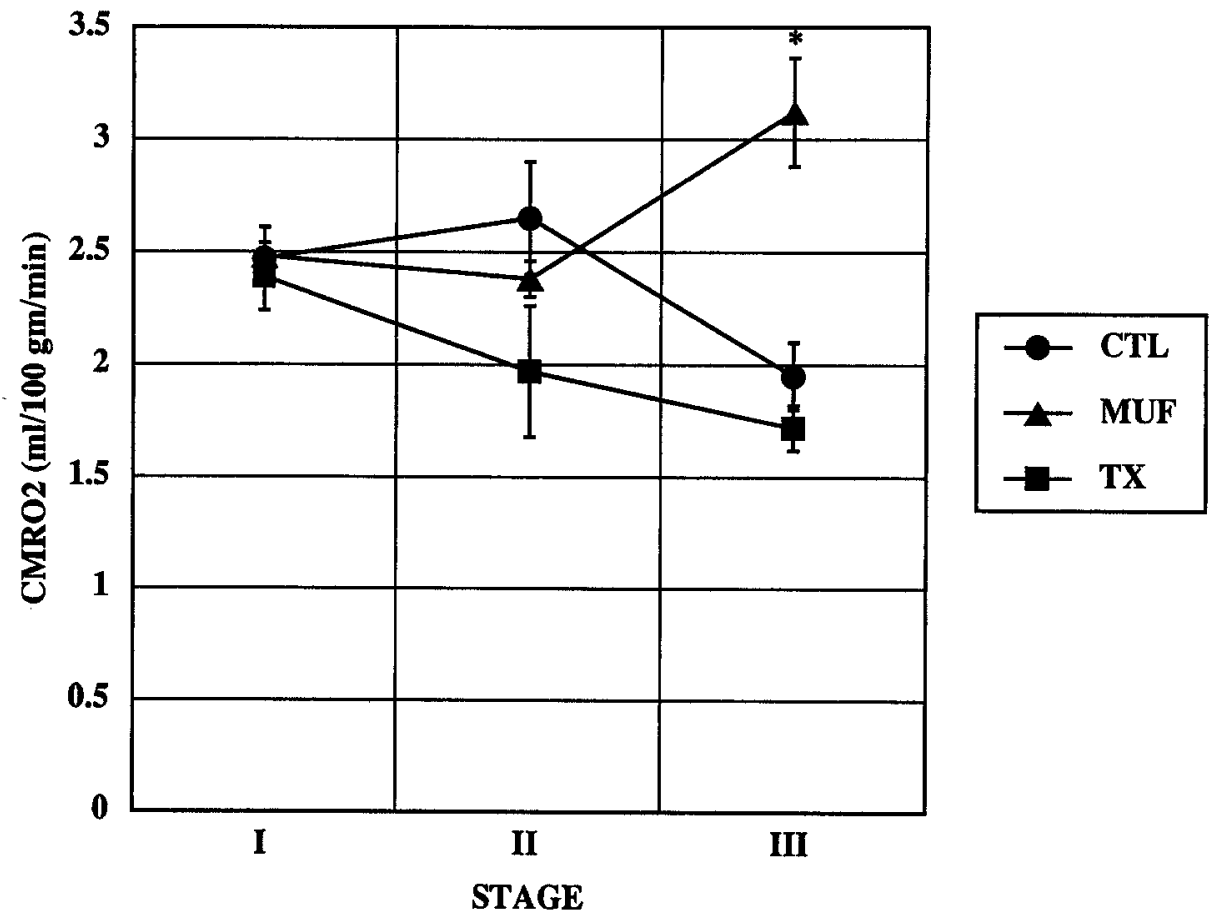

Fig. 4. $\mathrm{CMRO}_{2}$ measurements before and after DHCA. There was a significant increase in $\mathrm{CMRO}_{2}$ in MUF animals compared with CTL and Tx groups at stage III. Mean data \pm standard error; ${ }^{*} p<0.001$, MUF versus CTL and Tx. $C T L$, Control; $M U F$, ultrafiltration; $T x$, transfusion. $I$, Before CPB; $I I, 5$ minutes after CPB; $I I I, 25$ minutes after CPB.

maximal recovery of neurologic function is unknown. A high level of oxygen use may be needed to restore cellular stores depleted during the period of ischemia. Return of $\mathrm{CMRO}_{2}$ to pre-CPB values may be inadequate and could result in continuing cellular injury. After DHCA, control and transfused animals have a similar impairment in cerebral metabolism 25 minutes after separation from CPB, suggesting that $\mathrm{CMRO}_{2}$ is independent of cerebral oxygen delivery (Fig. 5). When cerebral oxygen delivery is increased by transfusion, $\mathrm{CMRO}_{2}$ does not increase and cerebral oxygen extraction falls, suggesting that the brain cannot use the additional oxygen. This finding emphasizes that the injury seen in this model after DHCA is one of limited oxygen use by the brain. This level of oxygen use after DHCA may be less than is needed for optimal cellular recovery. The ability of MUF to increase both cerebral oxygen delivery and $\mathrm{CMRO}_{2}$ after DHCA suggests that the supply and demand relationship has changed. It appears that the MUF animals are on a different oxygen supply and demand curve than the control and transfused animals. The MUF animals are able to use the additional oxygen delivered to the brain. This is demonstrated not only by an increase in $\mathrm{CMRO}_{2}$ but also by the fact that cerebral oxygen extraction does not decrease in the face of an elevation in cerebral oxygen delivery. This high level of oxygen use may be necessary to repay the oxygen debt incurred during arrest. It is not known from this study whether $\mathrm{CMRO}_{2}$ after MUF is maximal or if it could be increased even more by other interventions. Long-term neurologic outcome studies will be needed to determine the ideal level of $\mathrm{CMRO}_{2}$ after DHCA necessary for maximal recovery of neurologic function.

Possible mechanisms for the improvement in oxygen use by the brain after MUF include decreased cerebral edema, removal of toxic substances, and alteration of leukocyte-mediated injury. Total body water is increased after CPB and may result in tissue edema and organ dysfunction. The increase in total body water is greatest in patients with low weights and younger ages who undergo long periods of hypothermic low-flow CPB. ${ }^{27}$ MUF has been shown to decrease postoperative total body water in these 


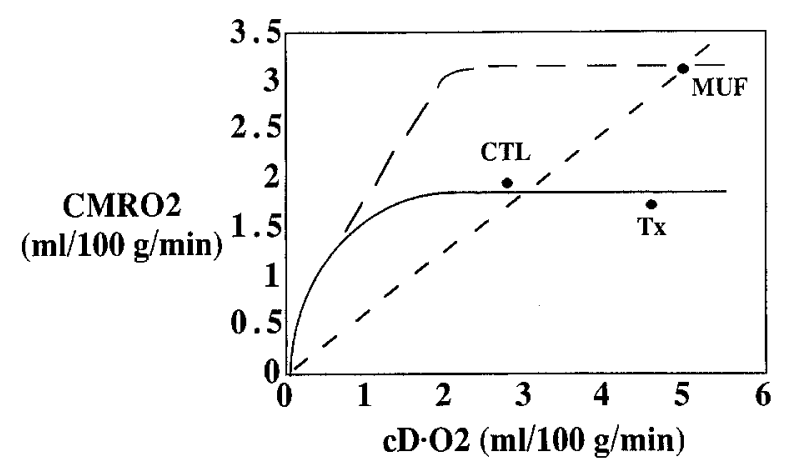

Fig. 5. Hypothetical cerebral oxygen supply and demand curves at 25 minutes after separation from CPB after DHCA. In this model $\mathrm{CMRO}_{2}$ does not change significantly with varying levels of cerebral oxygen delivery $\left(\mathrm{cD} \cdot \mathrm{O}_{2}\right)$, suggesting that control and transfusion animals are on the supply-independent (flat) portion of the curve. The ability of MUF to increase both $\mathrm{cD} \cdot \mathrm{O}_{2}$ and $\mathrm{CMRO}_{2}$ implies that these animals are on a different curve than control and transfusion animals. From the current study it cannot be determined if the MUF animals are on the supply-dependent (straight dotted line) or supply-independent (curved dotted line) portion of the curve.

patients. ${ }^{15}$ The reduction in total body water after MUF may decrease cerebral edema, thereby improving diffusion and use of oxygen by the brain.

Analysis of the filtrate after standard hemofiltration in adult patients during CPB revealed toxic peptides such as myocardial depressant factor and other vasoactive factors. ${ }^{28}$ Serum levels of tumor necrosis factor, a cytokine responsible for leukocyte adhesion and increased vascular permeability, were significantly reduced after operations in children who underwent hemofiltration during $\mathrm{CPB}$, and high levels of tumor necrosis factor were detected in the filtrate. ${ }^{29}$ MUF has also been shown to reduce serum levels of interleukin-8, a neutrophil chemotactic factor, in children undergoing CPB. ${ }^{30}$ Further studies will need to be performed for the means by which MUF improves oxygen use by the brain to be fully understood.

There are several limitations to this study. The cerebral metabolic response patterns demonstrated in these animals are acute changes only. However, recent investigations have demonstrated that DHCA is associated with an impairment in longterm neurologic outcome that may be related to the pattern of cerebral metabolic recovery seen in the immediate post-CPB period. ${ }^{31}$ The measurements of $\mathrm{CBF}$ are global and do not provide information about regional blood flow. However, this method of
CBF measurement was chosen to parallel methods used in patients at this institution, therefore making results produced in the laboratory setting clinically applicable. The brains were not examined histologically or on a molecular level. Further studies will need to be performed to help understand these acute changes in cerebral metabolism on a molecular level.

In summary, this study demonstrates that 90 minutes of DHCA results in impaired $\mathrm{CMRO}_{2} 25$ minutes after separation from CPB, consistent with previous experimental and clinical studies. 5, 6 Initially the mechanism for decreased $\mathrm{CMRO}_{2}$ after DHCA appeared to be a decrease in cerebral oxygen delivery. However, simply increasing cerebral oxygen delivery by raising the hematocrit value did not improve $\mathrm{CMRO}_{2}$ and cerebral metabolism remained impaired. After MUF, cerebral oxygen delivery and $\mathrm{CMRO}_{2}$ both increase and indicate that the brain can recover from metabolic dysfunction after DHCA. This ability to acutely improve cerebral metabolism after DHCA has not been previously demonstrated. High levels of $\mathrm{CMRO}_{2}$ after DHCA may be necessary to repay the debt incurred during arrest. Thus the return of $\mathrm{CMRO}_{2}$ to pre-CPB levels may not signify an absence of cerebral injury. It may be possible to reduce brain injury associated with DHCA by using MUF to improve cerebral oxygen use after the patient has been weaned from CPB. This improvement in cerebral oxygen delivery and use after separation from CPB may also prevent further neuropsychologic injury caused by low cardiac output, hypotension, or hypoxemia in the post-CPB period.

\section{REFERENCES}

1. Ferry PC. Neurologic sequelae of cardiac surgery in children. Am J Dis Child 1987;141:309-12.

2. Ferry PC. Neurologic sequelae of open-heart surgery in children: an "irritating question." Am J Dis Child 1990;144:369-73.

3. Newburger JW, Jonas RA, Wernovsky G, et al. A comparison of the perioperative neurologic effects of hypothermic circulatory arrest versus low-flow cardiopulmonary bypass in infant heart surgery. N Engl J Med 1993;329:1057-64.

4. Greeley WJ, Bracey VA, Ungerleider RM, et al. Recovery of cerebral metabolism and mitochrondrial oxidation state are delayed after hypothermic circulatory arrest. Circulation 1991;82(Suppl):III412-8.

5. Greeley WJ, Kern FH, Ungerleider RM, et al. The effect of hypothermic cardiopulmonary bypass and 
total circulatory arrest on cerebral metabolism in neonates, infants, and children. J THORAC CARDIOVASC SURG 1991;101:783-94.

6. Mault JR, Ohtake S, Klingensmith ME, et al. Cerebral metabolism and circulatory arrest: effects of duration and strategies for protection. Ann Thorac Surg 1993;55:57-64.

7. Mault JR, Whitaker EG, Heinle JS, et al. Effects of a second period of circulatory arrest on the brain. Ann Thorac Surg [In press].

8. Greeley WJ, Kern FH, Mault JR, et al. Mechanisms of injury and methods of protection of the brain during cardiac surgery in neonates and infants. Cardiol Young 1993;3:317-30.

9. Greeley WJ, Ungerleider RM, Smith LR, et al. The effects of deep hypothermic cardiopulmonary bypass and total circulatory arrest on cerebral blood flow in infants and children. J THORAC CARDIOVASC SURG 1989;97:737-45.

10. Griepp EV, Griepp RB. Cerebral consequences of hypothermic circulatory arrest in adults. J Card Surg 1992; 7:134-54.

11. Mezrow CK, Midulla PS, Sadeghi AM, et al. Evaluation of cerebral metabolism and quantitative electroencephalography after hypothermic circulatory arrest and low-flow cardiopulmonary bypass at different temperatures. J THORAC CARDIOvASC SuRG 1994;107: 1006-19.

12. Mezrow CK, Sadeghi AM, Gandsas A, et al. Cerebral effects of low-flow cardiopulmonary bypass and hypothermic circulatory arrest. Ann Thorac Surg 1994;57: 532-9.

13. Naik SK, Knight A, Elliott MJ. A successful modification of ultrafiltration for cardiopulmonary bypass in children. Perfusion 1991;6:41-50.

14. Elliott MJ. Ultrafiltration and modified ultrafiltration in pediatric open heart operations. Ann Thorac Surg 1993;56:1518-22.

15. Naik SK, Knight A, Elliott M. A prospective randomized study of a modified technique of ultrafiltration during pediatric open-heart surgery. Circulation 1991; 84(Suppl):III422-31.

16. Naik SK, Elliott MJ. Ultrafiltration and paediatric cardiopulmonary bypass. Perfusion 1993;8:101-12.

17. Spahn DR, Quill TJ, Hu WC, et al. Validation of ${ }^{133} \mathrm{Xe}$ clearance as a cerebral blood flow measurement technique during cardiopulmonary bypass. J Cereb Blood Flow Metab 1992;12:155-61.

18. Oleson J, Paulson OB, Lassen NA. Regional cerebral blood flow in man determined by the initial slope of the clearance of intraarterially injected ${ }^{133} \mathrm{Xe}$. Stroke 1971;2:519-25.

19. Chen RYZ, Fan FC, Kim S, et al. Tissue-blood partition coefficient for xenon: temperature and hematocrit dependence. J Appl Physiol 1980;49:178-83.

20. Gillinov AM, Redmond JM, Zehr KJ, et al. Superior cerebral protection with profound hypothermia during circulatory arrest. Ann Thorac Surg 1993;55: 1432-9.

21. Bellinger DC, Wernovsky G, Rappaport LA, et al. Rapid cooling of infants on cardiopulmonary bypass adversely affects later cognitive function. Circulation 1988;78:A358.

22. Aoki M, Nomura F, Stromski ME, et al. Effects of $\mathrm{pH}$ on brain energetics after hypothermic circulatory arrest. Ann Thorac Surg 1993;55:1093-103.

23. Hindman BJ, Dexter F, Cutkomp J, et al. Brain blood flow and metabolism do not decrease at stable brain temperature during cardiopulmonary bypass in rabbits. Anesthesiology 1992;77:342-51.

24. Swain JA, McDonald TJ, Griffith PK, et al. Low flow hypothermic cardiopulmonary bypass protects the brain. J Thorac Cardiovasc Surg 1991;102:76-84.

25. Watanabe $\mathrm{T}$, Miura $\mathrm{M}$, Orita $\mathrm{H}$, et al. Brain tissue $\mathrm{pH}$, oxygen tension, and carbon dioxide tension in profoundly hypothermic cardiopulmonary bypass: pulsatile assistance for circulatory arrest, low-flow perfusion, and moderate-flow perfusion. $J$ THORAC Cardiovasc Surg 1990;100:274-80.

26. Watanabe T, Orita $H$, Kobayashi M, et al. Brain tissue $\mathrm{pH}$, oxygen tension, and carbon dioxide tension in profoundly hypothermic cardiopulmonary bypass. J Thorac Cardiovasc Surg 1989;97:396-401.

27. Maehara T, Novak RKH, Elliott MJ. Perioperative monitoring of total body water by bio-electrical impedance in children undergoing open heart surgery. Eur J Cardiothorac Surg 1991;5:258-65.

28. Coraim F, Wolner E. Management of cardiac surgery patients with continuous arteriovenous hemofiltration. In: Sieberth H-G, Mann H, ed. Continuous arteriovenous hemofiltration (CAVH). Basel: Karger, 1985;103-10.

29. Millar AB, Armstrong L, van der Linden J, et al. Cytokine production and hemofiltration in children undergoing cardiopulmonary bypass. Ann Thorac Surg 1993;56:1499-502.

30. El Habbal M, Smith L, Strobel S, et al. Modified ultrafiltration after cardiopulmonary bypass for repair of ventricular septal defect reduces serum IL-8. Circulation 1993;88(Suppl):I96.

31. Croughwell ND, Newman MF, Blumenthal JA, et al. Jugular venous saturation and cerebral arterial venous difference predict cognitive dysfunction after cardiac surgery. Circulation 1993;88(Suppl):I289.

\section{Discussion}

Dr. Richard A. Jonas (Boston, Mass.). This is a most interesting result. Obviously all of us wonder about the mechanisms. You stated that you thought the result might be related to a reduction in cerebral edema. Did you in fact measure the water content of the brains?

Dr. Skaryak. We did not.

Dr. Jonas. $\mathrm{CMRO}_{2}$ is exquisitely sensitive to tempera- 
ture. With the technique of MUF that you have described, I understand that blood is passing from the reservoir through the heat exchanger. Therefore, you are pumping warm oxygenated blood into the patient with the MUF circuit. Did you measure directly cerebral temperature to exclude the possibility that this result simply represents a temperature-related effect on $\mathrm{CMRO}_{2}$ ?

Dr. Skaryak. We placed a temperature probe in the subcortical region of the brain. There were no differences between groups in subcortical brain temperatures 25 minutes after separation from CPB.

Dr. Julie A. Swain (Las Vegas, Nev.). Did you measure cerebral perfusion pressure or intercranial pressure?

Dr. Skaryak. We did not measure cerebral perfusion pressure or intracerebral pressure.

Dr. Randall B. Griepp (New York, N.Y.). The implications of this work are exciting. I would like to comment, however, on a consistent discrepancy between your work and ours with regard to $\mathrm{CMRO}_{2}$ in the early postoperative period. In our puppy model, in which blood flow is measured by microspheres, we do not demonstrate a reduction in $\mathrm{CMRO}_{2}$ even in animals subjected to a period of arrest that results in clinical and electroencephalographic evidence of cerebral injury. In your pig model with CBF being measured by radioactive xenon clearance, you consistently demonstrate a reduction of $\mathrm{CMRO}_{2}$ in early postoperative period. I think it is possible that the results that you have presented may provide a possible explanation for this discrepancy. Our experimental model is a survival one, and to get a puppy through a period of $\mathrm{CPB}$ and circulatory arrest, it is necessary to keep the animal extremely dry; accordingly, we are parsimonious with regard to fluid administration throughout the experimental period. In your model in which you do not need to be concerned about weaning from respiratory support, it may be possible that at the end of the experimental period the animals have some degree of cerebral edema. With reduction of cerebral edema by $\mathrm{MUF}, \mathrm{CMRO}_{2}$ returns to normal. Thus I am asking you to comment on the possibility that the explanation for your results is not necessarily a lower titer of inflammatory mediators, but rather a reduction in cerebral edema.

Dr. Skaryak. A decrease in cerebral edema is one possible mechanism of how MUF works. Martin Elliott and colleagues have shown that MUF reduces total body water accumulation, especially in younger, lower weight patients undergoing hypothermic low-flow bypass. Other studies have demonstrated that tumor necrosis factor and interleukin-8 levels were decreased in patients after MUF. Coraim and colleagues analyzed the ultrafiltrate and found a peak in high molecular weight peptides, very similar to myocardial depressant factor, suggesting that elimination of toxic peptides could be a possible mechanism. 